\title{
Long-Horizon Consumption Risk and the Cross-Section of Returns: New Tests and International Evidence
}

\author{
Joachim Grammig* Andreas Schrimpf ${ }^{\dagger} \quad$ Michael Schuppli ${ }^{\ddagger}$
}

This draft: August 28, 2008

This paper investigates whether measuring consumption risk over long horizons can improve the empirical performance of the Consumption CAPM for size and value premia in international stock markets (US, UK, and Germany). We modify the estimation approach of Parker and Julliard (2005) taking commonalities in size and book-to-market sorted portfolios into account. Our results show that, contrary to the findings of Parker and Julliard, the model falls short of providing an accurate description of the cross-section of returns under our modified empirical approach. At the same time, however, measuring consumption risk over longer horizons typically yields lower risk-aversion estimates. Thus, our results suggest that more plausible parameter estimates - as opposed to lower pricing errors - can be regarded as the main achievement of the long-horizon Consumption CAPM.

JEL Classification: G12, G15

Keywords: Consumption-based Asset Pricing, Long-Run Consumption Risk, Value Puzzle, International Stock Markets

* University of Tübingen, Department of Economics, Mohlstr. 36, D-72074 Tübingen, Germany, email: joachim.grammig@uni-tuebingen.de, phone: +49 (0)7071-29-78159.

$\dagger \quad$ Centre for European Economic Research (ZEW, Mannheim), P.O. Box 1034 43, D-68034 Mannheim, Germany, email: schrimpf@zew.de, phone: +49 (0)621-1235-160.

$\ddagger \quad$ University of Münster, Department of Economics, Am Stadtgraben 9, D-48143 Münster, Germany, email: michael.schuppli@wiwi.uni-muenster.de, phone: +49 (0)251-83-25001. 


\section{Introduction}

Understanding the behavior of asset prices and their relation to macroeconomic risks can be considered as one of the most fundamental issues in finance. As is well known, however, the traditional workhorse for studying the link between financial markets and the real economy - the consumption-based asset pricing model (CCAPM) - has failed to explain a number of stylized facts in finance such as the equity premium (Mehra and Prescott, 1985), asset return volatility (Grossman and Shiller, 1982) or value and size premia in the cross-section of expected returns (Cochrane, 1996; Lettau and Ludvigson, 2001). ${ }^{1}$ After a long series of poor empirical results starting with Hansen and Singleton (1982, 1983), more recent studies exploring the basic insights of the consumption-based asset pricing paradigm report encouraging advances (Cochrane, 2007, p.267).

In particular, a recent contribution by Parker and Julliard (2005) suggests to relate asset returns to consumption growth measured over longer horizons within a simple consumptionbased framework with CRRA preferences. Such reasoning is in line with theoretical literature on long-run consumption risk. Seminal work by Bansal and Yaron (2004) suggests that equilibrium asset returns depend on investors' expectations about both short and long-run changes in consumption growth. Among other things, this result implies that the covariance of returns with contemporaneous consumption growth may understate the risk perceived by investors. $^{2}$ By explicitly accounting for consumption risk over longer horizons, Parker and Julliard's long-horizon (LH) CCAPM is able to explain a large fraction of cross-sectional variation in expected returns across US size and book-to-market sorted portfolios. $^{3}$

In this paper, we provide new detailed evidence as to whether long-run consumption risk helps explain the cross-section of expected returns in international stock markets. In par-

$1 \quad$ The consumption-based asset pricing model has its roots in the original articles by Rubinstein (1976), Lucas (1978), and Breeden (1979). We use the terms CCAPM and consumption-based model interchangeably in the remainder of the paper.

2 Research on the long-run implications of the consumption-based asset pricing framework has constituted a rather prominent field in recent literature [e.g. Jagannathan and Wang (2007), Bansal, Dittmar, and Kiku (2007), Hansen, Heaton, and Li (2008) or Rangvid (2008)]. More detailed information on how our paper is related to the extant literature is provided in Section 2.2.

3 We will abbreviate the long-horizon CCAPM to LH-CCAPM in the remainder of the text. 
ticular, we modify Parker and Julliard's empirical approach along two lines. First, we take into account recent criticism about the widespread use of size and book-to-market sorted portfolios in the empirical asset pricing literature (Phalippou, 2007; Lewellen, Nagel, and Shanken, 2007). In order to reduce the adverse effects of strong commonalities in size and book-to-market sorted portfolios, we follow the prescription of Lewellen, Nagel, and Shanken (2007) to include industry portfolios alongside with the conventionally used size and book-to-market portfolios. Second, we provide new international evidence by investigating the model's explanatory power for the cross-section of equity returns in the United Kingdom and Germany.

Our empirical findings shed new light on the relative merits of the long-horizon CCAPM when it comes to explaining the cross-section of returns in international stock markets. First, we find that under our modified empirical approach accounting for the strong common factor structure in size and book-to-market sorted portfolios, the model's ability to account for cross-sectional variation in returns is clearly limited. This result suggests that the good empirical performance on US test assets reported by Parker and Julliard (2005) may be somewhat overstated. Tests with size and book-to-market sorted portfolios from the UK and Germany further corroborate the US evidence. Second, we find that measuring consumption risk over longer horizons typically yields lower risk-aversion estimates. Thus, our results suggest that more plausible parameter estimates - as opposed to a higher crosssectional $R^{2}$ - can be viewed as the main achievement of the long-horizon consumptionbased approach.

Even though the long-run risk framework has important implications for the explanation of risk premia and asset price fluctuations, previous empirical studies surveyed by Bansal (2007) have almost exclusively focussed on the US stock market. By estimating the proposed consumption-based model on UK and German portfolio returns, our paper explores the universality of the LH-CCAPM approach and, more generally, the role of long-run consumption risk in these markets.

This issue is particularly interesting since the countries considered in our study differ in several institutional respects. While the US and the UK for instance are known to have 
a market-based financial system and high private stock-ownership, Germany has a bankbased system and the share of stocks in the net wealth position of German households is lower. Furthermore, some authors have argued that the well-known US "equity premium puzzle" (i.e. the inability of the consumption based approach to quantitatively explain the high level of aggregate stock market returns compared to the T-Bill rate) may to some extent be due to extraordinarily high historical stock returns in the US during the postwar period [See, e.g., the discussion in (Cochrane, 2007, p.266)]. ${ }^{4}$ By contrast, post WWII excess returns on the German stock market have been somewhat lower.

The remainder of the text is structured as follows. Section 2 reviews the basic long-horizon consumption risk approach and provides a discussion on the literature most closely related to our paper. Section 3 describes the empirical methods used for estimating and evaluating the different models. Section 4 presents our data and discusses empirical results based on GMM estimation. Finally, Section 5 concludes.

\section{The Long-Horizon Consumption Risk Framework}

\subsection{Parker and Julliard's Basic Model}

This section briefly reviews the long-horizon consumption-based asset pricing approach put forth by Parker and Julliard (2005). As a starting point, consider the traditional twoperiod consumption-based model. As is well known, the model implies Euler equations of the following form

$$
\mathbb{E}_{t}\left[\delta \frac{u^{\prime}\left(C_{t+1}\right)}{u^{\prime}\left(C_{t}\right)} R_{t+1}^{e}\right]=0
$$

where $u($.$) denotes current-period utility, \delta$ the subjective time discount factor, and $R_{t+1}^{e}$ the excess return on a risky asset. Empirical tests of consumption-based models are typically based on moment conditions implied by variants of Equation (1). Parker and Julliard

$4 \quad$ Some financial economists also argue that expected excess returns are likely to be lower in the future, thus reducing the puzzle [See e.g. Fama and French (2000), Welch (2001)]. 
(2005) use the model's first order condition for the risk-free rate between points in time $\mathrm{t}+1$ and $\mathrm{t}+1+\mathrm{S}$

$$
u^{\prime}\left(C_{t+1}\right)=\delta \mathbb{E}_{t+1}\left[R_{t+1, t+1+S}^{f} u^{\prime}\left(C_{t+1+S}\right)\right]
$$

to substitute out period $t+1$ marginal utility in the above Euler equation. Assuming power utility and $\delta \approx 1$, Equation (1) can thus be rewritten as

$$
\mathbb{E}_{t}\left[m_{t+1}^{S} R_{t+1}^{e}\right]=0
$$

where $m_{t+1}^{S}=R_{t+1, t+1+S}^{f}\left(\frac{C_{t+1+S}}{C_{t}}\right)^{-\gamma}$ is the stochastic discount factor (SDF) and S denotes the horizon at which consumption growth is measured. As shown by Malloy, Moskowitz, and Vissing-Jørgensen (2006), a very similar stochastic discount factor can be derived in the Epstein and Zin (1989) recursive utility framework of Hansen, Heaton, and Li (2008). Using unconditional instead of conditional moments and rearranging yields an expression for the expected excess return

$$
\mathbb{E}\left[R_{i, t+1}^{e}\right]=-\frac{\operatorname{Cov}\left[m_{t+1}^{S}, R_{i, t+1}^{e}\right]}{\mathbb{E}\left[m_{t+1}^{S}\right]},
$$

which is similar to the case of the standard model except that the excess return now depends on its covariance with marginal utility growth over a longer time-horizon. In other words, investors demand a higher risk premium on assets whose return is more positively correlated with consumption growth over a long horizon. Parker and Julliard (2005) refer to the covariance of an asset's excess return with the modified SDF as "ultimate consumption risk".

The model's asset pricing implications can be tested either by directly estimating the nonlinear specification given by Equation (3), or by using the representation given by (4). Alternatively, the model can be estimated in its linearized form: Applying a first-order log-linear approximation in the spirit of Lettau and Ludvigson (2001) of the SDF yields 


$$
m_{t+1}^{S}=R_{t, t+1+S}^{f}-\gamma_{S} R_{t, t+1+S}^{f} \Delta c_{t+1+S}
$$

where $\Delta c_{t+1+S}=\ln \left(C_{t+1+S} / C_{t}\right)$ represents $\log$ consumption growth from t to $\mathrm{t}+1+\mathrm{S}$. Hence, the model using the linearized SDF in (5) can be interpreted as a linear two-factor model. Furthermore, assuming the risk-free rate to be constant between $t$ and $t+1+S$, the linear approximation reduces to a single factor model where the pricing kernel is a function of log consumption growth over long horizons.

\subsection{Related Literature and Further Motivation}

An important aspect of the proposed long-horizon CCAPM is that, in addition to retaining the parsimony of the power utility specification, it does not impair the basic assumptions of the consumption-based asset pricing framework. Yet, at the same time, the approach is consistent with various arguments why the covariance of an asset's return with contemporaneous consumption growth may understate its risk due to slow consumption adjustment. First, a wide range of factors not considered in the basic model, such as different sources of income, housing and durable goods consumption, may enter the utility function. In this case, the utility function is non-separable in that marginal utility with respect to one argument will always depend on the value of the other arguments. In addition, some of the consumption goods entering the utility function may involve a commitment (Chetty and Szeidl, 2005). Obviously, the adjustment of durable goods and housing consumption requires households to incur considerable transaction costs. Moreover, many services such as telecommunications are typically subject to long-term contracts. These real-world features imply that aggregate consumption adjustment may be slow.

Second, due to market imperfections such as costs of gathering and processing information, agents' short-term behavior may deviate from utility-maximizing consumption smoothing. In the presence of such frictions, investors may not optimally adjust consumption or rebalance their portfolio if utility losses from non-optimal behavior are small in magnitude (Cochrane, 1989). Such "near-rational" behavior appears plausible especially in the short- 
run. Again, from an empirical point of view, the reaction of consumption to changes in aggregate wealth will probably not be reflected in quarterly observations so that long-horizon consumption growth provides a more exact measure of perceived consumption risk.

Furthermore, the CCAPM of Parker and Julliard (2005) is closely related to a growing body of literature suggesting that investors require a premium on long-run consumption risk in asset returns. Pioneering theoretical work by Bansal and Yaron (2004) models consumption and dividend growth as containing a small persistent predictable component. Therefore, current shocks to expected growth will affect expectations about consumption growth in both the short and long run. From a theoretical point of view, the proposed consumption and dividend process can be motivated by explicitly modeling a production economy as in Kaltenbrunner and Lochstoer (2007). ${ }^{5}$ Bansal and Yaron (2004) show that in an economy with Epstein-Zin investor preferences, this additional source of risk helps to explain longstanding issues in finance such as the equity premium, low risk-free rates, high stock market volatility, and the predictive power of price-dividend ratios for longhorizon stock returns. In addition, the long-run risk framework has strong implications for the cross-section of expected asset returns. If representative agents are concerned about both short and long-run consumption risk, they will require higher risk premia on assets that are correlated with long-run consumption growth. Modeling dividend and consumption growth as a VAR, Bansal, Dittmar, and Lundblad (2005) determine the exposure of dividends to long-run consumption risk. They show that this exposure helps explain a large fraction of cross-sectional variation in returns across book-to-market, size and momentum portfolios. Other recent papers documenting the relevance of long-run consumption risk for determining equilibrium asset returns include Bansal, Dittmar, and Kiku (2007), Hansen, Heaton, and Li (2008), Malloy, Moskowitz, and Vissing-Jørgensen (2006), and Colacito and Croce (2007).

In sum, a large body of evidence for the US suggests that consumption growth measured over longer horizons may be an important risk factor explaining cross-sectional variation in returns. Indeed, Parker and Julliard (2005) show that the cross-sectional $R^{2}$ obtained

$5 \quad$ The existence of a persistent component in consumption and dividends is empirically confirmed by Bansal, Kiku, and Yaron (2007). 
when estimating the model on 25 US book-to-market and size portfolios increases with the horizon at which consumption growth is measured. In fact, the non-linear model explains up to $44 \%$ of the cross-sectional variation in average excess returns for a horizon of 11 quarters. In this respect, the model's performance is similar to the conditional CCAPM of Lettau and Ludvigson (2001) and the Fama and French (1993) three factor model. This finding seems to suggest that long-run risk may help resolve the value premium puzzle.

Another prominent drawback of the canonical CCAPM with CRRA utility is that, given the observed risk premia, estimated coefficients of relative risk aversion are usually implausibly high (Hansen and Singleton, 1983). This aspect is at the center of recent work by Rangvid (2008), who tests an international LH-CCAPM using world-consumption growth as a risk factor on excess aggregate stock market returns from 16 developed capital markets. The author shows that risk aversion estimates for an internationally diversified investor decrease substantially to more plausible values if long-run consumption risk is taken into account. However, the beta-pricing version of the model has trouble explaining the cross-section of international stock index returns.

It is important to note that his empirical approach is based on the strong assumption of an international representative investor, integrated financial markets, and purchasing power parity. This paper, in contrast, analyzes the ability of the LH-CCAPM to explain the individual cross-section of stock returns in three major stock markets. Besides requiring weaker assumptions, looking at only three countries enables us to use detailed consumption data that distinguish expenditure on nondurable goods and services from durable goods (rather than having to rely on measures of total consumption). Moreover, it allows us to pin down pricing errors for individual stock portfolios formed on characteristics such as size and book-to-market equity ratios, which have been of particular interest in the empirical finance literature. 


\section{Empirical Methodology}

In this section we outline our empirical approach for exploring the performance of the long-horizon consumption-based asset pricing framework. Moment restrictions necessary to estimate any model for the stochastic discount factor by the Generalized Method of Moments (GMM) can be derived from Euler equations similar to Equation (3). Nonetheless, we opt for the slightly different GMM estimation strategy employed by Parker and Julliard (2005), using moment conditions based on the expression for expected excess returns in Equation (4). There are three reasons for doing this: First, closely following Parker and Julliard's approach renders our empirical results comparable to theirs. Second, as we will illustrate below, their approach allows us to empirically disentangle a model's ability to explain the equity premium from its explanatory power for cross-sectional variation in stock returns. Third, this approach provides an intuitive interpretation of our GMM estimation results: Using the moment restrictions in Equation (4) implies that the difference between empirical and theoretical moments can be interpreted as errors in expected returns, which in turn are proportional to pricing errors. These pricing errors will be directly comparable across models. More specifically, consider the vector of unconditional moment restrictions

$$
\mathbb{E}\left[h\left(\Theta_{t+1}, \mu_{S}, \gamma_{S}, \alpha_{S}\right)\right]=0,
$$

where $\Theta_{t+1}$ represents the data (the vector of $\mathrm{N}$ test asset excess returns and consumption growth), whereas the model parameters are given as $\mu_{S}$ (mean of the stochastic discount factor $\left.m_{t+1}^{S}\right)$ and $\gamma_{S}$ (risk aversion parameter of the representative agent). For the nonlinear model introduced in Section 2.1, the $(\mathrm{N}+1) \times 1$ empirical moment function $h($.$) is given$ by

$$
h\left(\Theta_{t+1}, \mu_{S}, \gamma_{S}, \alpha_{S}\right)=\left[\begin{array}{c}
\mathbf{R}_{t+1}^{e}-\alpha_{S} \iota_{N}+\frac{\left(m_{t+1}^{S}-\mu_{S}\right) R_{t+1}^{e}}{\mu_{S}} \\
m_{t+1}^{S}-\mu_{S}
\end{array}\right]
$$

where $\mathbf{R}_{t+1}^{e}$ denotes the vector of $\mathrm{N}$ test asset excess returns and $\iota_{N}$ is an N-dimensional 
vector of ones. ${ }^{6}$ Notice that the point estimate for $\alpha_{S}$ will be expressed in units of expected returns. Therefore, including the parameter in the moment function in Equation (7) allows us to directly determine the magnitude of a model's implied "equity premium puzzle", i.e., to investigate whether a candidate model is able to explain the overall level of test asset returns compared to the level of the risk-free rate.

We modify the estimation approach by Parker and Julliard (2005) in one important dimension. In a recent contribution, Lewellen, Nagel, and Shanken (2007) highlight the statistical problems associated with the common use of size and book-to-market sorted portfolios in the empirical asset pricing literature. In particular, given the strong factor structure of these portfolios, Lewellen, Nagel, and Shanken (2007) point out that any model incorporating factors that are strongly correlated with SMB and HML potentially produces a high cross-sectional $R^{2}$ when tested on these test assets. In order to avoid these problems, we expand the set of test assets to include industry portfolios along with the commonly used size and book-to-market sorted portfolios. This implies that our modified empirical approach provides a clearly tougher challenge for the candidate asset pricing models compared to Parker and Julliard (2005).

In addition to testing the nonlinear long-horizon consumption-based model, we also compare the empirical performance of the linearized LH-CCAPM in Equation (5) to traditional factor models such as the CAPM and the Fama and French (1993) model. The moment function for the three candidate factor models differs slightly from the nonlinear model, reflecting the linear approximation of the stochastic discount factor. Let $\mathbf{f}_{t+1}$ denote the vector of $\mathrm{k}$ factors, $\mu$ the vector of estimated factor means, and $\mathbf{b}$ the vector of coefficients measuring the marginal effect of the respective factors on the SDF. The $(\mathrm{N}+\mathrm{k}) \times 1$ moment function can then be written as

$$
h\left(\Theta_{t+1}, \mu, \mathbf{b}, \alpha\right)=\left[\begin{array}{c}
\mathbf{R}_{t+1}^{e}-\alpha_{S} \iota_{N}+\mathbf{R}_{t+1}^{e}\left(\mathbf{f}_{t+1}-\mu\right)^{\prime} \mathbf{b} \\
\mathbf{f}_{t+1}-\mu
\end{array}\right]
$$

\footnotetext{
$\overline{6} \quad$ The last moment condition is intended to identify the mean of the SDF, i.e. there are $\mathrm{N}+1 \mathrm{moment}$
} conditions in total. 
This moment function satisfies $\mathrm{N}+\mathrm{k}$ unconditional moment restrictions given by

$$
\mathbb{E}\left[h\left(\Theta_{t+1}, \mu, \mathbf{b}, \alpha\right)\right]=0,
$$

which can be used to estimate the parameters of the model by GMM. In this context, it is important to note that identification of the parameters of the linear model requires some normalization. Using demeaned factors in the moment function in Equation 8 achieves this, but it also implies that we have to correct standard errors for the fact that factor means are estimated along the way. Therefore we use the augmented moment function in Equation 8, which imposes additional restrictions on the deviation of factors from their estimated means. ${ }^{7}$

In general, the GMM framework allows for various choices of the matrix determining the weights of individual moments in the objective function. As discussed in detail in Cochrane (2005, Ch. 11), the particular choice of weighting matrix affects both statistical properties and economic interpretation of the estimates: Even though second or higher stage GMM estimates based on the optimal weighting matrix of Hansen (1982) are efficient, they are difficult to interpret economically as they imply pricing some random combination of reweighted portfolios. Instead, relying on first stage estimates with equal weights compromises efficiency while maintaining the economic interpretation of empirical tests. Therefore, our discussion of empirical results in Section 4 centers on first stage GMM estimates. In addition, we also report results from the "test of overidentifying restrictions" based on iterated GMM estimation as a test of overall model fit. An alternative advocated by Hansen and Jagannathan (1997) is to use the inverse of the second moment matrix of returns as a first stage weighting matrix. This approach allows us to compute the corresponding Hansen-Jagannathan distance, which serves as an additional metric for model comparison.

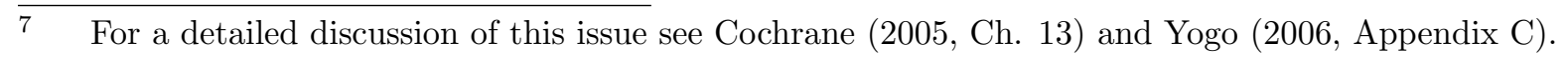




\section{Empirical Analysis}

\subsection{Data}

This section provides a detailed overview of the data used in this paper. Data on personal consumption expenditure are available from national institutions in the respective country: the US Bureau of Economic Analysis (BEA), the UK Office for National Statistics (ONS), and the Federal Statistical Office (Destatis) in Germany. As is customary in the literature on consumption-based asset pricing, we use a measure of household's consumption of nondurable goods and services obtained from the official statistics. We divide by quarterly population figures to express consumption in per capita terms. Finally, all consumption time-series are deflated by the respective consumer price index.

While data on different consumption categories (nondurables, durables and services) are readily available at the quarterly frequency for both the US and the UK, this is not the case for Germany. We therefore use detailed annual data on personal consumption expenditures for different items to construct the share of nondurables and services in total consumption per annum. In order to estimate quarterly per capita expenditure on nondurables and services, we assign the same share to all quarterly total expenditure observations within a given year. ${ }^{8}$ Another important aspect is the effect of Germany's reunification on consumption data. We correct for the negative outlier in the one-period (per capita) consumption growth rate due to the reunification using interpolation as in Stock and Watson (2003). Longer-horizon growth rates are then based on the corrected series.

Our choice of test assets is mainly guided by two considerations. First, our aim is to analyze the ability of the long-horizon CCAPM to price the cross-section of stock returns in major financial markets outside the United States. Second, following the suggestions of Lewellen, Nagel, and Shanken (2007), we use a broad set of test assets including portfolios sorted on both book-to-market and size as well as industry. This choice is intended to avoid problems arising from strong commonalities in size and book-to-market sorted portfolios.

$8 \quad$ We experimented with various other matching procedures including quadratic polynomials and cubic splines, but found only negligible differences. 
As is standard in the empirical literature, our set of test assets contains 25 US value and size portfolios introduced by Fama and French (1993). Similar portfolios capturing both size and value premia are constructed by Dimson, Nagel, and Quigley (2003) for the United Kingdom ${ }^{9}$ and by Schrimpf, Schröder, and Stehle (2007) for Germany. The total number of listed stocks in the UK and Germany is much smaller than in the US. Therefore, in both cases, stocks are sorted into merely 16 portfolios in order to avoid potential biases in portfolio returns. For comparisons with traditional asset pricing models such as the CAPM and the Fama and French (1993) three factor model, we obtain data on market returns, the excess return of small over big market capitalization firms (SMB), and the excess return of high versus low book-to-market firms (HML) from the same sources.

Returns on ten US industry portfolios sorted according to SIC codes are available from Kenneth French's website. ${ }^{10}$ In case of the UK, we use seven industry portfolios obtained from Datastream which are available for the longest possible sample period matching the one of the other UK test assets. Our industry portfolios for the German stock market are obtained from the German Finance Database (Deutsche Finanzdatenbank) maintained at the University of Karlsruhe. ${ }^{11}$ We compute excess returns on all portfolios using a countryspecific proxy for the risk-free rate: For the US and the UK, we use a 3-month T-bill rate and, in the case of Germany, a 3-month money market rate provided by Deutsche Bundesbank is used. Finally, we compute real returns using the respective national consumer price index $(\mathrm{CPI}) .^{12}$

\subsection{Empirical Results: Non-Linear Model}

As pointed out in Section 3, we estimate the nonlinear LH-CCAPM for each of the three markets separately using the Generalized Method of Moments (GMM). Our discussion of

\footnotetext{
9 Returns on the 16 portfolios as well as Market, HML and SMB factors can be downloaded from Stefan Nagel's webpage: http://faculty-gsb.stanford.edu/nagel

10 http://mba.tuck.dartmouth.edu/pages/faculty/ken.french/

11 The sample periods for test asset returns cover 1947:Q2 - 2001:Q4 for the US, 1965:Q2 - 2001:Q1 for the UK, and 1974:Q2 - 2001:Q1 for Germany. The overall sample period, however, is longer due to the long-horizon consumption growth (up to S) aligned to the returns: US (2004:Q3), UK (2003:Q4), GER (2003:Q4).

12 CPI data for the US, the UK and Germany are available from the BEA, the IMF International Financial Statistics and the OECD Economic Outlook, respectively.
} 
empirical results focuses mainly on three aspects: a candidate model's ability to explain the equity premium $(\hat{\alpha})$, the plausibility of the estimated risk-aversion parameter $(\hat{\gamma})$, and the cross-sectional explanatory power as reflected by the cross-sectional $R^{2}$ and pricing error plots. ${ }^{13}$ In addition, we report results from J-tests based on iterated GMM estimates, the root mean squared error (RMSE) from first stage GMM estimation, and the HJ-distance metric proposed by Hansen and Jagannathan (1997).

Our results for the US, reported in Table 1, complement the evidence in Table 1 of Parker and Julliard (2005) and provide a reassessment of their findings under our modified empirical approach. ${ }^{14}$ It is important to keep in mind that we use an expanded set of test assets by adding 10 industry portfolios to the usual 25 Fama-French portfolios. As evinced by Table 1, the risk-aversion estimate for the standard CCAPM $(S=0)$ is rather large, mirroring previous results in the literature. It is worth noting, however, that the estimated RRA coefficient typically decreases to substantially lower values as we move from short to longterm consumption risk. Moreover, the precision of the estimates tends to increase with the horizon. As the significant $\hat{\alpha}$ estimates show, a major limitation of the LH-CCAPM is the failure to explain the "equity premium", i.e. the overall level of stock returns in relation to the risk-free rate. In contrast to results reported by Parker and Julliard (2005), its magnitude hardly declines as the consumption growth horizon increases. Thus, the model leaves unexplained a substantial fraction of the excess return of stocks over the risk-free rate. $^{15}$

[Insert Table 1 about here]

Most importantly, however, our results presented in Table 1 suggest that the singular use of size and book-to-market portfolios [as in Parker and Julliard (2005)] may overstate the

13 Computation of the cross-sectional $R^{2}$ in the GMM estimation framework follows Jagannathan and Wang (1996) and Parker and Julliard (2005).

14 In order to render our results comparable across countries, we limit the horizon at which long-run consumption risk is measured to 11 quarters.

15 The J-test rejects all short and long-horizon specifications of the CCAPM, which is a common finding in the empirical asset pricing literature: Even the best performing models such as the Fama-French three factor model are often rejected by formal statistical tests [e.g. Lettau and Ludvigson (2001)]. 
empirical performance of the long-horizon CCAPM: If we include industry portfolios in our set of test assets, as advocated by Lewellen, Nagel, and Shanken (2007), we only find moderate improvements of the consumption-based asset pricing approach as the horizon of long-horizon consumption risk increases. Accordingly, the estimated $R^{2}$ reaches a maximum of $20 \%$ at a horizon of eleven quarters, which is half the value reported by Parker and Julliard (2005) for the same horizon. Therefore, the main empirical success of the the LHCCAPM seems to lie in more plausible estimates of the coefficient of relative risk-aversion, while the model's performance to explain the value premium still remains rather poor.

\section{[Insert Table 2 about here]}

Next, we provide estimation results on the performance of the LH-CCAPM for the crosssection of returns in the UK and Germany, where previous literature on cross-sectional tests of consumption-based asset pricing models has been rather scarce. ${ }^{16}$ Estimation results for the UK reported in Table 2 largely confirm our findings for the US. Even though the estimated coefficient of determination arrives at a peak at shorter consumption growth horizons of 3 and 7 quarters, the overall explanatory power of the LH-CCAPM remains comparably low. Moreover, the model cannot explain the overall level of UK stock returns. Nevertheless, the effect of long-horizon risk on risk-aversion estimates is again remarkable. If we measure consumption growth over a time period of at least 5 quarters following the return, the estimated risk-aversion coefficient declines to values around 5 .

Table 3 summarizes the evidence on the empirical content of the long-horizon CCAPM framework for the German stock market. The results for the LH-CCAPM in Germany are rather in line with those for the US stock market discussed above. As evinced by the Table, we find that the plausibility of parameter estimates varies with the consumption growth horizon. Most importantly, risk-aversion estimates tend to decline to more plausible levels as we increase the time period over which consumption growth is measured. However, this

\footnotetext{
16 An exception is the work of Gao and Huang (2004), who use UK value and size portfolios, whereas other papers such as Hyde and Sherif (2005a,b) for the UK and Lund and Engsted (1996) for Germany estimate consumption-based models separately for each industry sector or market index.
} 
decrease is not monotonous. At the same time, the estimated cross-sectional $R^{2}$ also varies with the horizon and reaches a maximum of $22 \%$ for $\mathrm{S}=11$.

[Insert Table 3 about here]

Interestingly, even the canonical consumption-based model does not imply an "equity premium puzzle" for Germany. What is more, the relevant coefficient $(\hat{\alpha})$ is further reduced if long-horizon consumption risk is taken into account. Overall, the results for the UK and the German stock markets further corroborate our earlier conclusion that, even though the ability of the LH-CCAPM to account for size and value premia is rather limited, the modified model helps to obtain more sensible risk-aversion parameter estimates.

\subsection{Empirical Results: Linearized Model}

In order to facilitate comparison with traditional factor models for the stochastic discount factor, we also estimate the linearized version of the LH-CCAPM. Tables 4, 5, and 6 summarize estimation results assuming a constant risk-free rate, which implies a one-factor model where long-horizon consumption growth serves as the single risk factor. In general, estimates are in accordance with those obtained for the nonlinear model.

As discussed in the previous subsection, when required to price a broader cross-section of assets, the long-horizon risk CCAPM apparently has trouble explaining US excess returns (Table 4). Nevertheless, our results confirm those of Parker and Julliard (2005) in two other regards. First, the cross-sectional $R^{2}$ increases considerably for longer horizons. Second, GMM coefficient estimates suggest that the effect of consumption growth on the representative investor's stochastic discount factor is estimated more precisely if consumption risk is measured over longer time periods. Moreover, the estimate of the risk-aversion coefficient declines to more economically plausible values as the horizon $\mathrm{S}$ increases.

[Insert Table 4 about here] 
[Insert Table 5 about here]

The explanatory power of the linearized LH-CCAPM for the cross-section of returns seems clearly weaker when tested on UK stock portfolios. Similar to estimation results for the nonlinear specification, the coefficient of determination is highest for horizons of $3(12 \%)$ and $7(9 \%)$ quarters. In addition, point estimates $\hat{b}$ suggest that the SDF is not systematically related to consumption risk, irrespective of the chosen horizon. Although implied risk-aversion estimates have high standard errors, they exhibit a considerable decline as we extend the horizon over which consumption risk is measured.

Results for the linearized version of the LH-CCAPM for the German stock market are provided in Table 6. As was the case for the nonlinear specification, the model has no problem explaining the the overall level of stock returns. Taking long-horizon risk into account improves the performance of the CCAPM in other respects. The empirical fit as measured by $R^{2}$ and RMSE is best for a consumption risk horizon of 11 quarters. Moreover, implied risk aversion appears to decrease with horizon (albeit in a non-monotonous fashion). If consumption risk is measured over 11 quarters, the coefficient of relative risk aversion is estimated at a rather low value of 10 which is half the point estimate obtained for the conventional CCAPM. Moreover, the significance of $\hat{b}$, the parameter measuring the effect of consumption growth on the SDF, is far higher for $\mathrm{S}=11$ than for the canonical CCAPM.

All together, inference for the linearized LH-CCAPM suggests that long-horizon consumption risk helps improve the empirical performance of the consumption-based model to some extent. Even though detailed empirical results differ across countries, some common patterns emerge. Most notably, measuring consumption risk over several quarters following the return helps to obtain much more plausible estimates of the representative investor's risk-aversion coefficient. This result is in accordance with recent evidence presented by Rangvid (2008).

[Insert Table 6 about here] 


\subsection{Comparison to Traditional Linear Factor Models}

Empirical results for the linearized CCAPM can be directly compared to those for the Fama and French (1993) three-factor model and the traditional CAPM, which are summarized in Table 7.

Estimates for 35 US portfolios in Panel A are in line with previous evidence in the literature [e.g. Fama and French (1993) or Lettau and Ludvigson (2001)]: While the Fama-French three factor model explains more than $50 \%$ of cross-sectional variation in returns, the standard CAPM performs extremely poorly. Accordingly, as shown in Figure 1, portfolio excess returns predicted by the CAPM appear to be almost unrelated to realized average excess returns. In contrast, fitted excess returns for the Fama-French model and, to a lesser extent, the LH-CCAPM line up more closely to the $45^{\circ}$ line. At the same time, estimation results in Table 7 also indicate that, with the exception of HML, none of the proposed Fama-French factors seem to significantly affect the SDF of the representative US investor.

As illustrated in Figure 2, the high explanatory power of the Fama and French (1993) model typically found for the US is even higher for the cross-section of UK stock returns. First stage GMM estimates reveal that the model explains as much as $71 \%$ of cross-sectional variation in returns, compared to only $6 \%$ for the CAPM and $9 \%$ for the canonical CCAPM $(\mathrm{S}=0)$. However, as can be seen in Table 7 , coefficients measuring the marginal impact of the respective financial risk factors on the SDF are not significant.

[Insert Table 7 about here]

[Insert Figure 1 about here]

[Insert Figure 2 about here] 
In the case of Germany (Panel $\mathrm{C}$ ), the cross-sectional $R^{2}$ obtained for the long-run risk model - up to about $20 \%$ at 11 quarters - is clearly qualified by the high explanatory power of the three factor model $(70 \%)$ and the CAPM (52\%). Actually, the CAPM performs surprisingly well when tested on a cross-section of 28 industry, value and size portfolios, as reflected by significant $\hat{b}$ estimates. Nevertheless, the three factor model performs even better in that it provides an explanation for the overall level of returns relative to the riskfree rate and is not rejected by the test of overidentifying restrictions at the $5 \%$ significance level. Comparing all three models in terms of their explanatory power for German stock returns, the long-run consumption risk model does not provide any advantages over the two traditional linear models based on financial factors. Pricing error plots in Figure 3 confirm this conclusion as the magnitude of pricing errors is considerably lower for the three-factor model of Fama and French (1993). ${ }^{17}$

Summing up, the empirical success of long-run consumption risk compared to the canonical CCAPM in terms of cross-sectional explanatory power is qualified by the astonishingly good performance of the factor model of Fama and French (1993). ${ }^{18}$ At the same time, our results for the UK and the US confirm the bad performance of the CAPM typically found in empirical model comparisons. Surprisingly, we find that this model explains as much as $52 \%$ of cross-sectional variation in returns across German portfolios. In any case, measuring risk in stock returns as their covariance with long-run consumption growth leads to some - but generally limited - improvements over the canonical CCAPM in terms of overall empirical fit. Our results for international stock markets show that value and size premia still remain a major challenge for the LH-CCAPM.

[Insert Figure 3 about here]

17 However, models using macroeconomic factors will always be at a disadvantage to models using financial factors (Cochrane, 2007, p.7) due to a less precise measurement of macroeconomic variables. Moreover, these models allow for a more structural analysis of the economic determinants of risk premia, which typically cannot be delivered by models using merely financial factors.

18 A major disadvantage of Fama and French's three factor model is that there is still no full agreement in the literature about what the true risks underlying SMB and HML actually are. See, e.g., Petkova (2006) for a risk-based explanation in an empirical implementation of an ICAPM in the spirit of Merton (1973). 


\section{Conclusion}

Recent work by Parker and Julliard (2005) suggests that measuring consumption growth over several quarters following the return substantially improves the explanatory power of the consumption-based asset pricing paradigm. Their modified empirical setup is robust against various arguments as to why consumption expenditure may be slow to adjust to innovations in aggregate wealth. Besides, their model is closely related to the literature on long-run consumption risk, as it implies expressions for expected returns that are similar to the testable implications of long-run risk models with recursive utility such as Hansen, Heaton, and Li (2008).

Our work contributes to the literature on long-run consumption risks in three respects: First, by expanding the set of test assets to include industry portfolios, we take into account recent criticism regarding the widespread use of value and size portfolios as test assets (Phalippou, 2007; Lewellen, Nagel, and Shanken, 2007). Under our modified empirical approach, we find that long-horizon consumption risk falls short of providing a complete account of the cross-section of expected returns, especially the premium on value stocks. In this way, our findings suggest that the long-horizon consumption-based approach does not resolve the famous "value premium puzzle".

Second, evaluating the proposed CCAPM separately for three countries enables us to compare results across capital markets. In this sense, our findings provide additional outof-sample evidence and address potential data-snooping concerns. Empirical results for Germany and the UK indicate that measuring consumption risk over longer horizons indeed helps increase the empirical performance of the CCAPM, albeit at modest levels. For both markets, estimated coefficients of determination remain below those obtained for the ad hoc factor model of Fama and French (1993).

Third, our analysis confirms the evidence of Parker and Julliard (2005), who find that point estimates of the investor's risk-aversion parameter vary with the time interval over which consumption growth is measured. In line with evidence reported by Rangvid (2008), we find that accounting for long-horizon consumption risk typically delivers more sensible 
estimates. This is true for all three equity markets considered in this study.

Summing up, accounting for long-horizon consumption risk within the CCAPM framework indeed seems to improve the model's cross-sectional explanatory power in certain ways. On the one hand, the model still falls short of providing an accurate description of size and value premia. On the other hand, the estimated risk aversion of an investor who is concerned about long-run consumption risk is much lower and therefore more plausible compared to the standard model. In this sense, long-horizon consumption risk appears to be a more accurate measure of macroeconomic risk factors in stock returns than contemporaneous consumption growth. 


\section{References}

Bansal, R. (2007): "Long-Run Risk and Financial Markets," NBER Working Paper 13196, National Bureau of Economic Research.

Bansal, R., R. Dittmar, and D. Kiku (2007): "Cointegration and Consumption Risks in Asset Returns," Forthcoming in Review of Financial Studies.

Bansal, R., R. F. Dittmar, and C. T. Lundblad (2005): "Consumption, Dividends, and the Cross Section of Equity Returns," Journal of Finance, 60(4), 1639-1672.

Bansal, R., D. Kiku, and A. Yaron (2007): "Risks For the Long Run: Estimation and Inference," Working paper, University of Pennsylvania.

Bansal, R., and A. Yaron (2004): "Risk for the Long Run: A Potential Resolution of Asset Pricing Puzzles," Journal of Finance, 59(4), 1481-1509.

Breeden, D. T. (1979): "An Intertemporal Asset Pricing Model with Stochastic Consumption and Investment Opportunities," Journal of Financial Economics, 7, 265-96.

Chetty, R., And A. Szeidl (2005): "Consumption Commitments: Neoclassical Foundations for Habit Formation," Working paper, UC Berkeley.

Cochrane, J. H. (1989): "The Sensitivity of Tests of the Intertemporal Allocation of Consumption to Near-Rational Alternatives," American Economic Review, 79(3), 319 337.

_ (1996): "A Cross-Sectional Test of an Investment-Based Asset Pricing Model," Journal of Political Economy, 104(3), 572-621.

— (2005): Asset Pricing. Princeton University Press, Princeton, NJ.

(2007): "Financial Markets and the Real Economy," in Handbook of the Equity Premium, ed. by R. Mehra, pp. 237-325. Elsevier.

Colacito, R., and M. M. Croce (2007): "Risks For The Long Run And The Real Exchange Rate," Discussion paper. 
Dimson, E., S. Nagel, and G. Quigley (2003): "Capturing the Value Premium in the United Kingdom," Financial Analysts Journal, 59(6), 35 - 45.

Epstein, L., And S. Zin (1989): "Substitution, Risk Aversion, and the Temporal Behavior of Consumption Growth and Asset Returns I: A Theoretical Framework," Econometrica, $57,937-969$.

Fama, E. F., And K. R. French (1993): "Common risk factors in the returns on stocks and bonds," Journal of Financial Economics, 33, 3-56.

(2000): "The Equity Premium," University of Chicago.

GaO, P., and K. X. Huang (2004): "Aggregate Consumption-Wealth Ratio and the Cross-Section of Stock Returns: Some International Evidence," Working Paper RWP 04-07, Federal Reserve Bank of Kansas City, Kansas City, MO.

Grossman, S. J., And R. J. Shiller (1982): "The Determinants of the Variability of Stock Market Prices," American Economic Review, 71, 222-227.

Hansen, L. P. (1982): "Large Sample Properties of Generalized Method of Moments Estimators," Econometrica, 50(4), 1029-1054.

Hansen, L. P., J. C. Heaton, and N. Li (2008): "Consumption Strikes Back?: Measuring Long-Run Risk," Forthcoming in Journal of Political Economy.

Hansen, L. P., and R. Jagannathan (1997): "Assessing Specification Errors in Stochastic Discount Factor Models," Journal of Finance, 52(2), 557-590.

Hansen, L. P., And K. J. Singleton (1982): "Generalized Instrumental Variables Estimation of Nonlinear Rational Expectations Models," Econometrica, 50(2), 12961286.

(1983): "Stochastic Consumption, Risk Aversion, and the Temporal Behavior of Asset Returns," Journal of Political Economy, 91, 249-265.

Hyde, S., And M. Sherif (2005a): "Consumption Asset Pricing Models: Evidence from the UK," The Manchester School, 73(3), 343 - 363. 
(2005b): "Don’t Break the Habit: Structual Stability Tests of Consumption Asset Pricing Models in the UK," Applied Economics Letters, 12, 289-296.

Jagannathan, R., And Y. Wang (2007): "Lazy Investors, Discretionary Consumption, and the Cross-Section of Stock Returns," Journal of Finance, 62(4), 1623-1661.

Jagannathan, R., And Z. Wang (1996): "The Conditional CAPM and the CrossSection of Expected Returns," Journal of Finance, 51(1), 3-53.

Kaltenbrunner, G., and L. A. Lochstoer (2007): "Long-Run Risk Through Consumption Smoothing," Working paper, London Business School.

Lettau, M., and S. Ludvigson (2001): "Ressurrecting the (C)CAPM: A Cross-Sectional Test when Risk Premia Are Time-Varying," Journal of Political Economy, 109, 12381287.

Lewellen, J., S. Nagel, And J. Shanken (2007): "A Skeptical Appraisal of AssetPricing Tests," Working paper, Stanford.

Lucas, Robert E., J. (1978): "Asset Prices in an Exchange Economy," Econometrica, 46(6), 1429-1445.

Lund, J., And T. Engsted (1996): "GMM and Present Value Tests of the C-CAPM: Evidence from the Danish, German, Swedish and UK Stock Markets," Journal of International Money and Finance, 15(4), 497 - 521.

Malloy, C. J., T. J. Moskowitz, and A. Vissing-Jørgensen (2006): "Long-Run Stockholder Consumption Risk and Asset Returns," Working paper, Northwestern University.

Mehra, R., And E. Prescott (1985): "The Equity Premium: A Puzzle," Journal of Monetary Economics, 15, 145-161.

Merton, R. C. (1973): "An Intertemporal Capital Asset Pricing Model," Econometrica, 41(5), 867-887. 
Parker, J. A., and C. Julliard (2005): "Consumption Risk and the Cross Section of Expected Returns," Journal of Political Economy, 113(1), 185 - 222.

Petkova, R. G. (2006): "Do the Fama-French Factors Proxy for Innovations in Predictive Variables?," Journal of Finance, 61(2), 581-612.

Phalippou, L. (2007): "Can Risk-Based Theories Explain the Value Premium?," Review of Finance, 11, 143 - 166.

RAngVID, J. (2008): "The Long-Run World Consumption Risk of International Stock Markets," Working paper, Copenhagen Business School.

Rubinstein, M. (1976): "The Valuation of Uncertain Income Streams and the Pricing of Options," Bell Journal of Economics, 7, 407-425.

Schrimpf, A., M. Schröder, and R. Stehle (2007): "Cross-Sectional Tests of Conditional Asset Pricing Models: Evidence from the German Stock Market," European Financial Management, 13(5), 880-907.

Stock, J. H., And M. W. Watson (2003): "Forecasting output and Inflation: The role of Asset Prices," Journal of Economic Literature, 151, 788-829.

Welch, I. (2001): "The Equity Premium Consensus Forecast Revisited," Working Paper, Brown University.

Yogo, M. (2006): "A consumption-based explanation of expected stock returns," Journal of Finance, 61(2), 539-580. 


\section{Tables and Figures}

Table 1: Consumption Risk and US Stock Returns - Nonlinear LH-CCAPM

\begin{tabular}{|c|c|c|c|c|c|c|}
\hline Horizon & $\begin{array}{c}\hat{\alpha} \\
\text { (std. err.) }\end{array}$ & $\begin{array}{c}\hat{\gamma} \\
\text { (std. err.) }\end{array}$ & $R^{2}$ & RMSE & $\begin{array}{l}\text { HJ-Dist. } \\
\text { (p-value) }\end{array}$ & $\begin{array}{c}\mathrm{J} \\
(\mathrm{p} \text {-value })\end{array}$ \\
\hline \multirow[t]{2}{*}{0} & 0.022 & 45.410 & 0.07 & 0.529 & 0.587 & 112.417 \\
\hline & $(0.005)$ & $(59.882)$ & & & $(0.000)$ & $(0.000)$ \\
\hline \multirow[t]{2}{*}{1} & 0.019 & 30.720 & 0.09 & 0.525 & 0.584 & 106.269 \\
\hline & $(0.005)$ & $(29.364)$ & & & $(0.000)$ & $(0.000)$ \\
\hline \multirow[t]{2}{*}{3} & 0.018 & 22.575 & 0.09 & 0.523 & 0.588 & 112.372 \\
\hline & $(0.006)$ & $(22.189)$ & & & $(0.001)$ & $(0.000)$ \\
\hline \multirow[t]{2}{*}{5} & 0.018 & 20.626 & 0.11 & 0.520 & 0.586 & 110.750 \\
\hline & $(0.005)$ & $(18.728)$ & & & $(0.005)$ & $(0.000)$ \\
\hline \multirow[t]{2}{*}{7} & 0.018 & 20.719 & 0.14 & 0.508 & 0.584 & 109.739 \\
\hline & $(0.005)$ & $(15.657)$ & & & $(0.009)$ & $(0.000)$ \\
\hline \multirow[t]{2}{*}{9} & 0.019 & 20.525 & 0.17 & 0.500 & 0.584 & 110.940 \\
\hline & $(0.004)$ & $(12.488)$ & & & $(0.012)$ & $(0.000)$ \\
\hline \multirow[t]{2}{*}{11} & 0.019 & 20.391 & 0.20 & 0.493 & 0.579 & 107.299 \\
\hline & $(0.004)$ & (11.031) & & & $(0.028)$ & $(0.000)$ \\
\hline
\end{tabular}

Note: The reported values for $\hat{\alpha}, \hat{\gamma}, R^{2}$, and the Root Mean Squared Error (RMSE) are computed using equal weights across portfolios (first stage GMM). The HJ-Distance is based on first stage GMM estimation using the weighting matrix proposed by Hansen and Jagannathan (1997), the J-statistic on iterated GMM estimation. The sample period is 1947:Q2 - 2001:Q4 for returns and 1947:Q2 - 2004:Q3 for quarterly consumption. 
Table 2: Consumption Risk and UK Stock Returns - Nonlinear LH-CCAPM

\begin{tabular}{|c|c|c|c|c|c|c|}
\hline Horizon & $\begin{array}{c}\hat{\alpha} \\
\text { (std. err.) }\end{array}$ & $\begin{array}{c}\hat{\gamma} \\
\text { (std. err.) }\end{array}$ & $R^{2}$ & RMSE & $\begin{array}{l}\text { HJ-Dist. } \\
\text { (p-value) }\end{array}$ & $\begin{array}{c}\mathrm{J} \\
(\mathrm{p} \text {-value })\end{array}$ \\
\hline \multirow[t]{2}{*}{0} & 0.025 & 14.787 & 0.09 & 0.671 & 0.505 & 48.102 \\
\hline & $(0.009)$ & $(27.133)$ & & & $(0.028)$ & $(0.001)$ \\
\hline \multirow[t]{2}{*}{1} & 0.024 & 3.685 & 0.01 & 0.700 & 0.501 & 45.177 \\
\hline & $(0.009)$ & $(22.583)$ & & & $(0.034)$ & $(0.002)$ \\
\hline \multirow[t]{2}{*}{3} & 0.021 & 15.012 & 0.14 & 0.654 & 0.500 & 49.357 \\
\hline & $(0.010)$ & $(17.637)$ & & & $(0.030)$ & $(0.000)$ \\
\hline \multirow[t]{2}{*}{5} & 0.023 & 5.651 & 0.05 & 0.686 & 0.498 & 47.964 \\
\hline & $(0.008)$ & $(14.625)$ & & & $(0.035)$ & $(0.001)$ \\
\hline \multirow[t]{2}{*}{7} & 0.021 & 8.950 & 0.13 & 0.656 & 0.497 & 48.309 \\
\hline & & & & & $(0.035)$ & $(0.001)$ \\
\hline \multirow[t]{2}{*}{9} & 0.023 & 4.517 & 0.07 & 0.680 & 0.499 & 47.405 \\
\hline & $(0.007)$ & $(11.782)$ & & & $(0.029)$ & $(0.001)$ \\
\hline \multirow[t]{2}{*}{11} & 0.022 & 5.037 & 0.09 & 0.671 & 0.496 & 47.800 \\
\hline & $(0.007)$ & (12.011) & & & $(0.027)$ & $(0.001)$ \\
\hline
\end{tabular}

Note: The reported values for $\hat{\alpha}, \hat{\gamma}, R^{2}$, and the Root Mean Squared Error (RMSE) are computed using equal weights across portfolios (first stage GMM). The HJ-Distance is based on first stage GMM estimation using the weighting matrix proposed by Hansen and Jagannathan (1997), the J-statistic on iterated GMM estimation. The sample period is 1965:Q2 - 2001:Q1 for returns and 1965:Q2 - 2003:Q4 for quarterly consumption. 
Table 3: Consumption Risk and German Stock Returns - Nonlinear LH-CCAPM

\begin{tabular}{ccccccc}
\hline \hline Horizon & $\begin{array}{c}\hat{\alpha} \\
\text { (std. err.) }\end{array}$ & $\begin{array}{c}\hat{\gamma} \\
\text { (std. err.) }\end{array}$ & $R^{2}$ & RMSE & $\begin{array}{c}\text { HJ-Dist. } \\
\text { (p-value) }\end{array}$ & $\begin{array}{c}\mathrm{J} \\
(\mathrm{p} \text {-value })\end{array}$ \\
\hline \multirow{2}{*}{0} & 0.015 & 61.927 & 0.09 & 0.730 & 0.544 & 61.121 \\
& $(0.009)$ & $(31.840)$ & & & $(0.362)$ & $(0.000)$ \\
\multirow{2}{*}{1} & 0.013 & 59.990 & 0.16 & 0.701 & 0.545 & 43.436 \\
& $(0.008)$ & $(36.956)$ & & & $(0.317)$ & $(0.017)$ \\
3 & 0.013 & 27.586 & 0.05 & 0.744 & 0.545 & 97.116 \\
& $(0.008)$ & $(37.379)$ & & & $(0.275)$ & $(0.000)$ \\
5 & 0.013 & 11.850 & 0.05 & 0.745 & 0.552 & 44.760 \\
& $(0.008)$ & $(27.171)$ & & & $(0.216)$ & $(0.013)$ \\
7 & 0.010 & 17.963 & 0.12 & 0.718 & 0.554 & 46.184 \\
& $(0.006)$ & $(19.539)$ & & & $(0.205)$ & $(0.009)$ \\
\multirow{2}{*}{9} & 0.012 & 11.482 & 0.09 & 0.726 & 0.551 & 45.088 \\
& $(0.006)$ & $(16.736)$ & & & $(0.203)$ & $(0.012)$ \\
\multirow{2}{*}{11} & 0.007 & 19.987 & 0.22 & 0.675 & 0.552 & 46.216 \\
& $(0.004)$ & $(17.863)$ & & & $(0.208)$ & $(0.009)$ \\
\hline \hline
\end{tabular}

Note: The reported values for $\hat{\alpha}, \hat{\gamma}, R^{2}$, and the Root Mean Squared Error (RMSE) are computed using equal weights across portfolios (first stage GMM). The HJ-Distance is based on first stage GMM estimation using the weighting matrix proposed by Hansen and Jagannathan (1997), the J-statistic on iterated GMM estimation. The sample period is 1974:Q2 - 2001:Q1 for returns and 1974:Q2 - 2003:Q4 for quarterly consumption. 


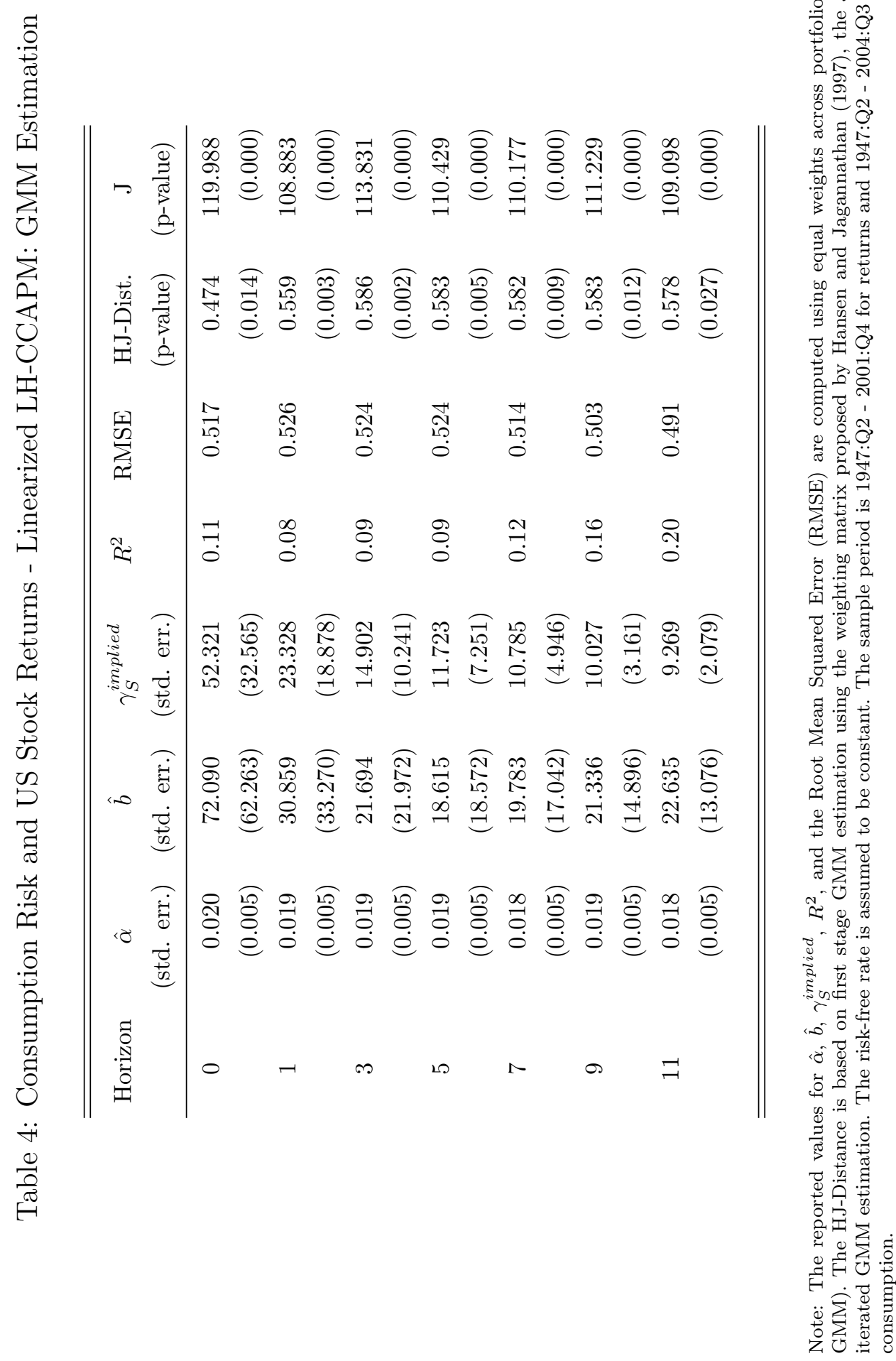




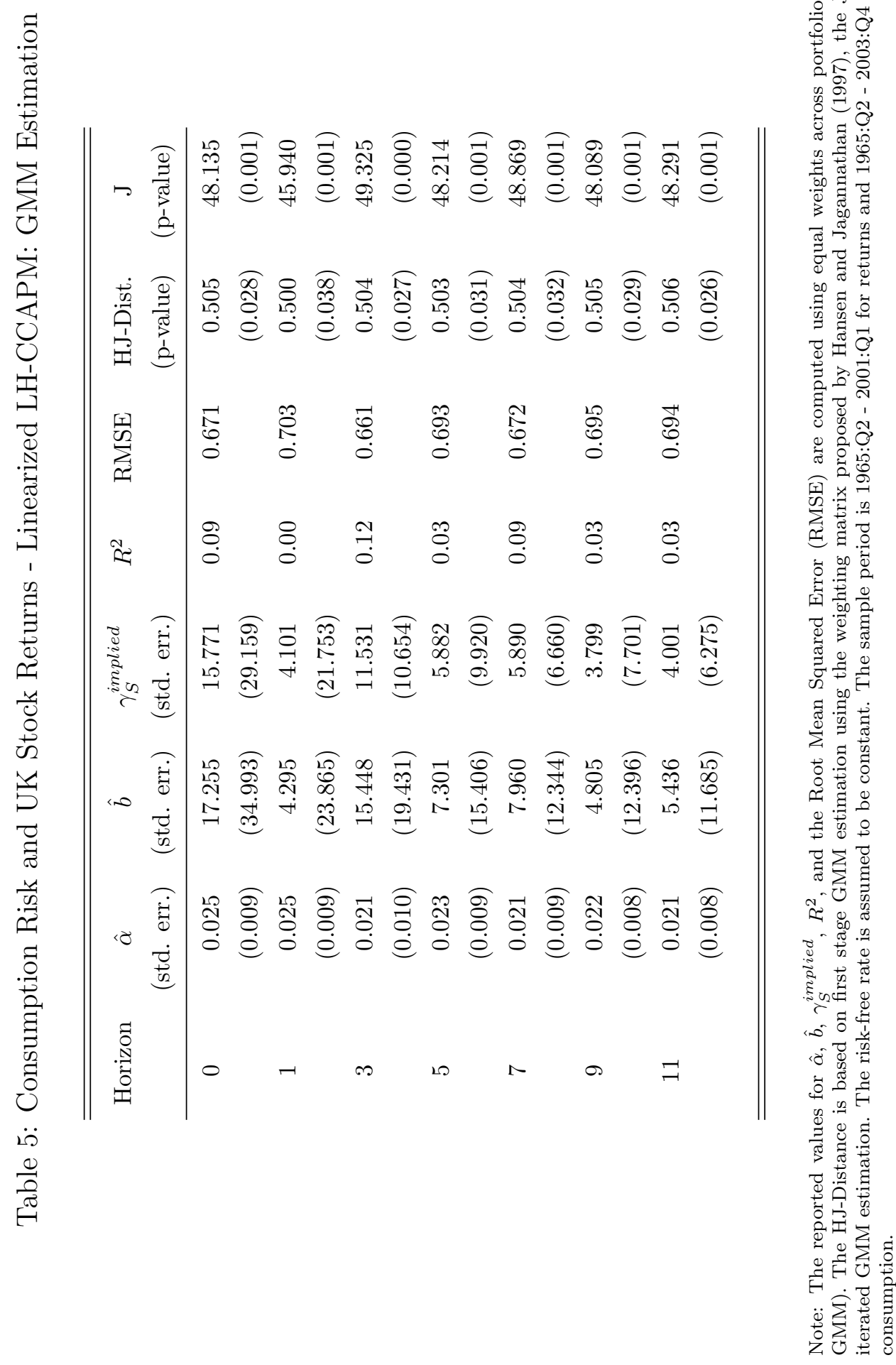




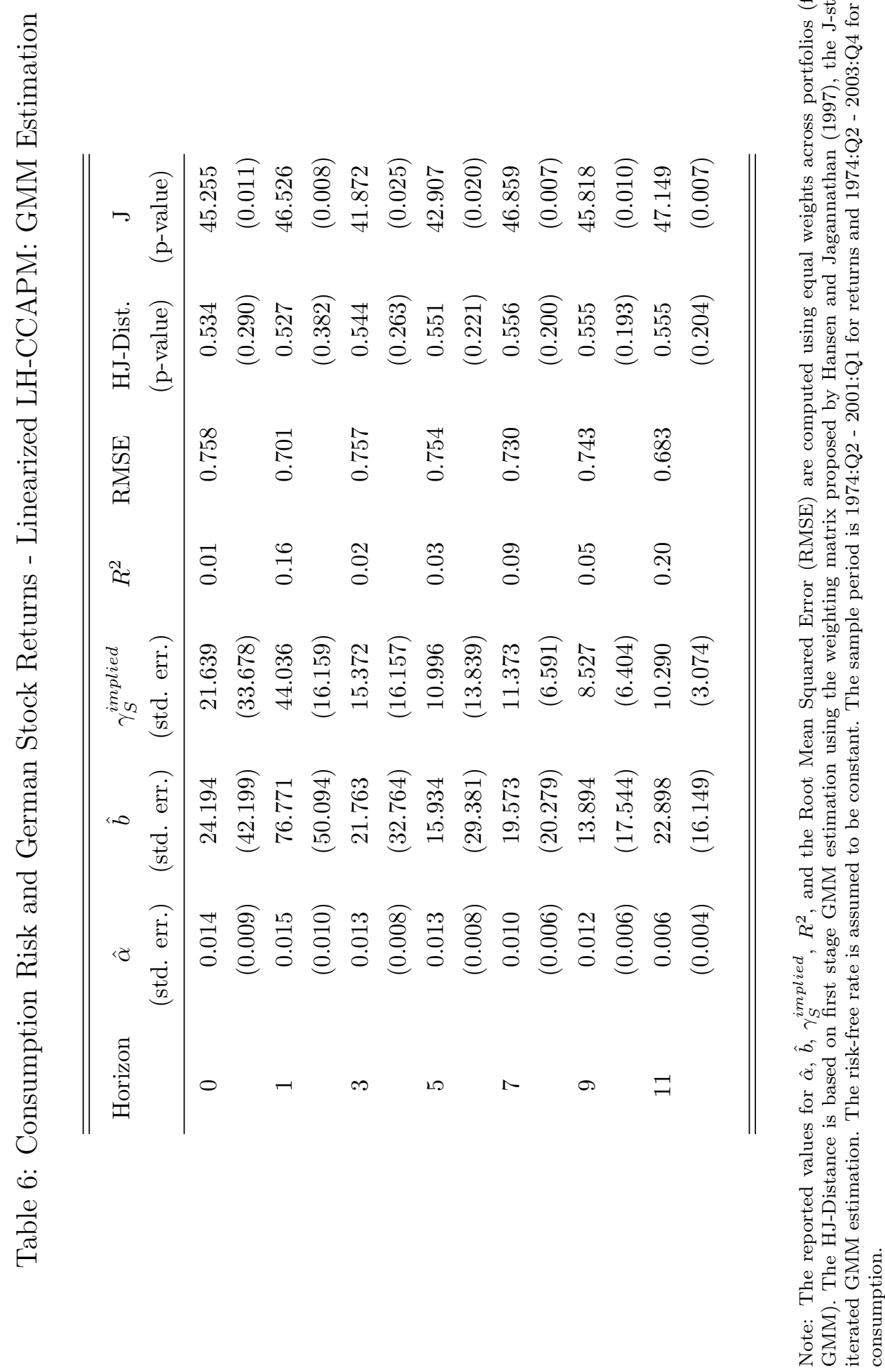




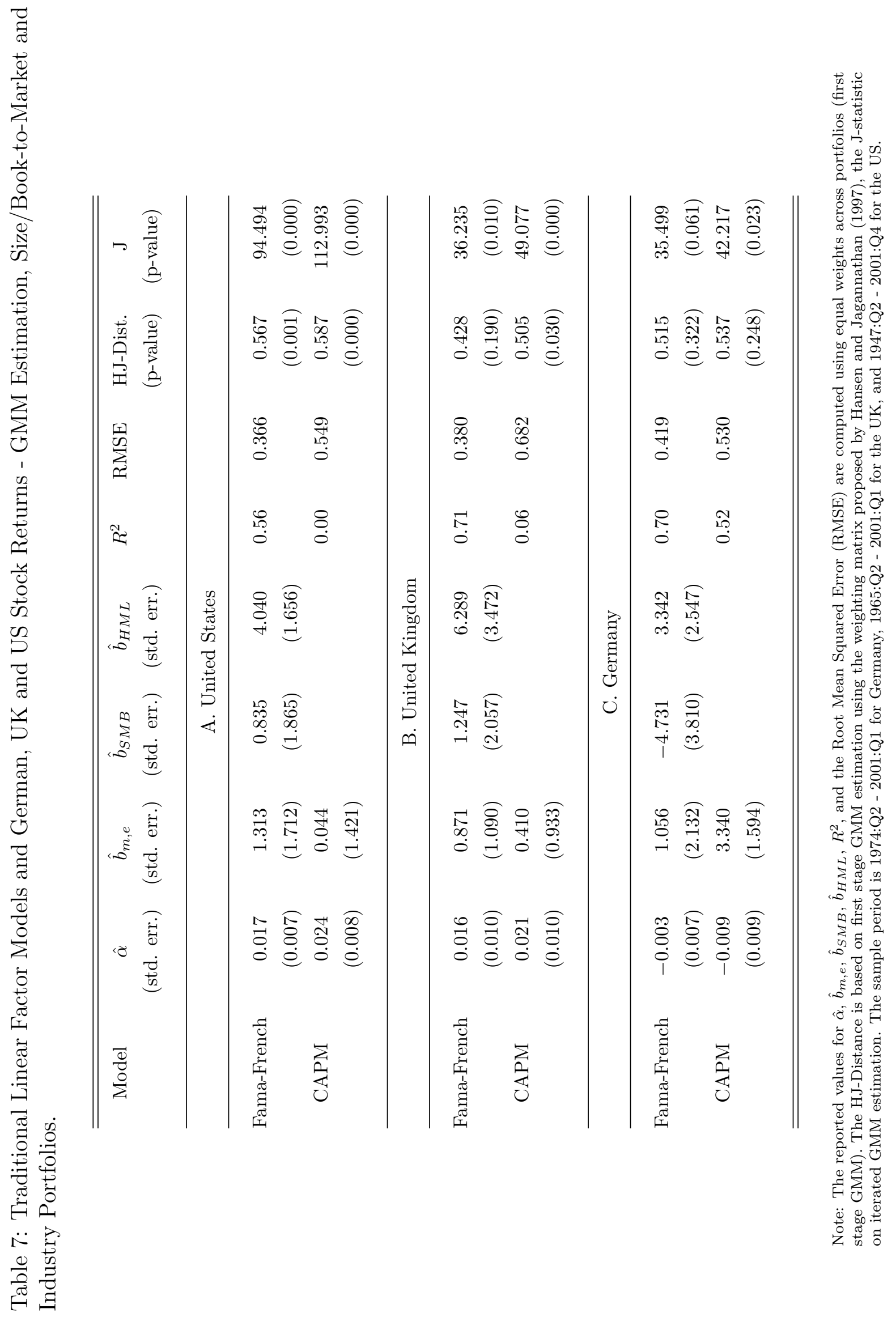


Figure 1: Pricing Error Plots for US Stock Returns - Linearized LH-CCAPM and Traditional Linear Factor Models
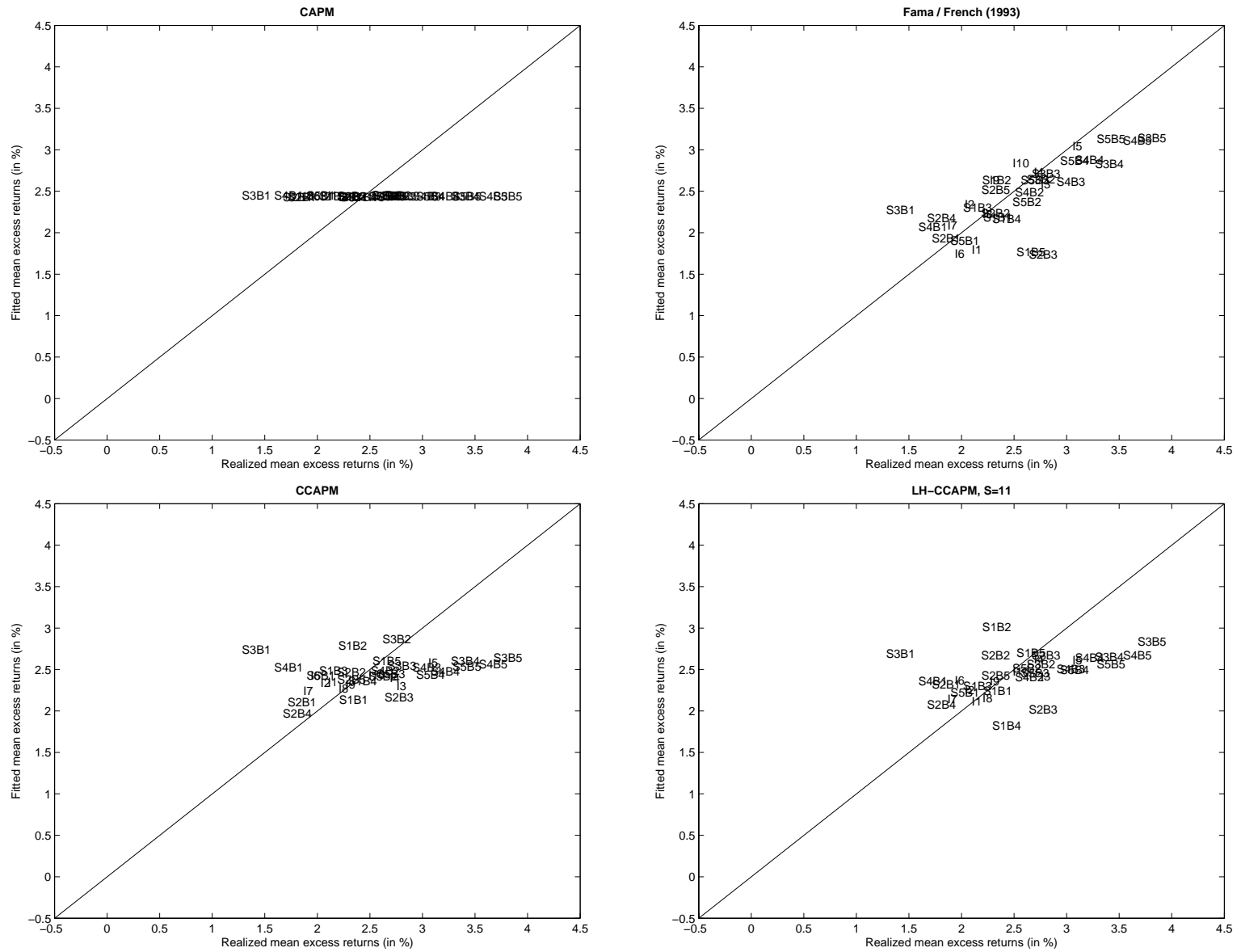

Note: The figure compares realized mean excess returns on 25 value and size as well as 10 industry portfolios to those predicted by the CAPM, the Fama and French (1993) model, and the linearized LH-CCAPM (with constant risk-free rate) at different horizons. The portfolios are depicted in the following way: e.g., S1B1 refers to stocks in the smallest size and book-to-market Quintiles, while S5B5 refers to stocks in the largest size and book-to-market Quintiles; industry portfolios are depicted as I plus the corresponding industry number running from 1 to 10 . Fitted excess returns are based on first stage GMM estimation with identity weighting matrix. The sample period is 1947:Q2 - 2001:Q4. 
Figure 2: Pricing Error Plots for UK Stock Returns - Linearized LH-CCAPM and Traditional Linear Factor Models
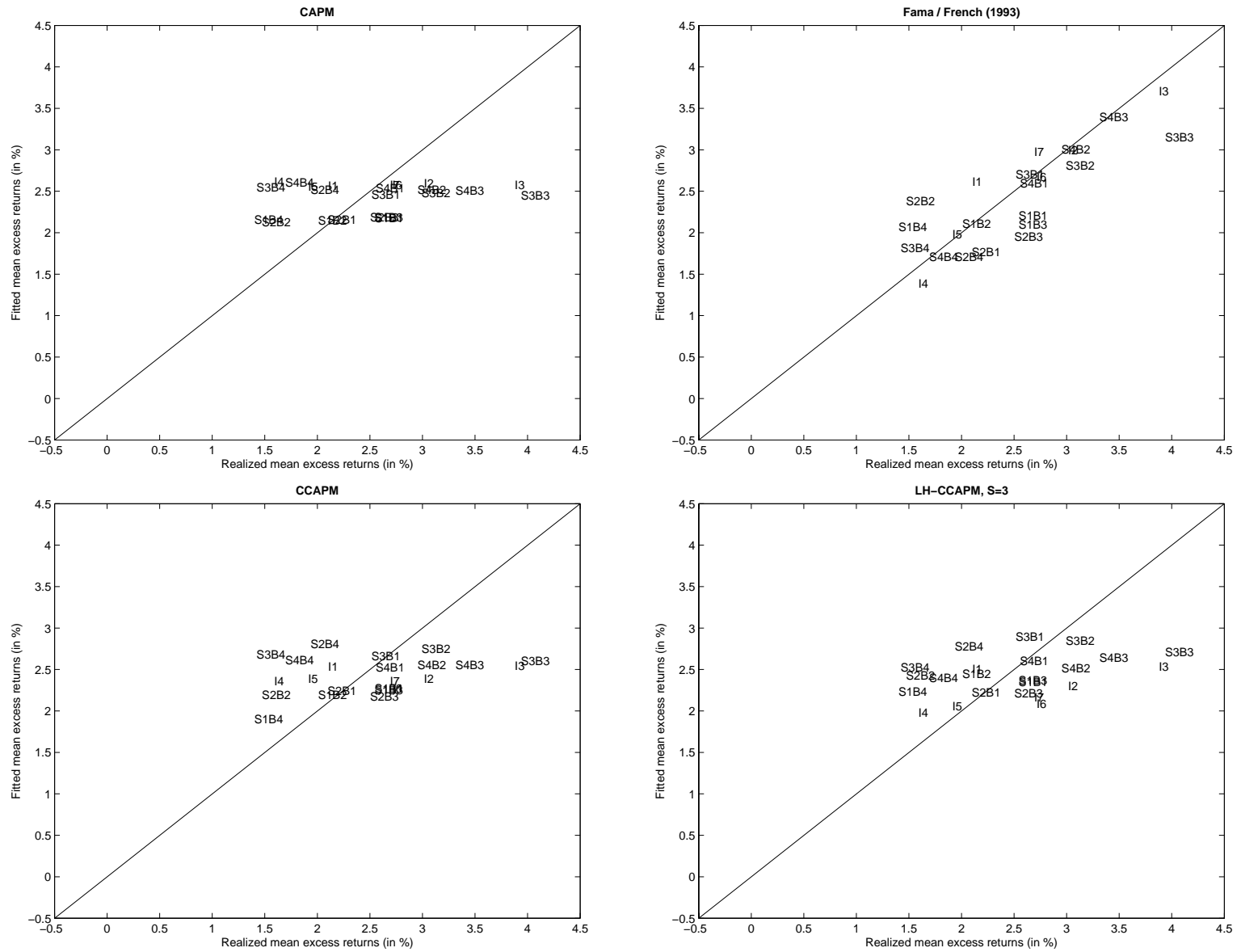

Note: The figure compares realized mean excess returns on 16 value and size as well as 7 industry portfolios to those predicted by the CAPM, the Fama and French (1993) model, and the linearized LH-CCAPM (with constant risk-free rate) at different horizons. The portfolios are depicted in the following way: e.g., S1B1 refers to stocks in the smallest size and book-to-market Quartiles, while S4B4 refers to stocks in the largest size and book-to-market Quartiles; industry portfolios are depicted as I plus the corresponding industry number running from 1 to 7 . Fitted excess returns are based on first stage GMM estimation with identity weighting matrix. The sample period is 1965:Q2 - 2001:Q1. 
Figure 3: Pricing Error Plots for German Stock Returns - Linearized LH-CCAPM and Traditional Linear Factor Models
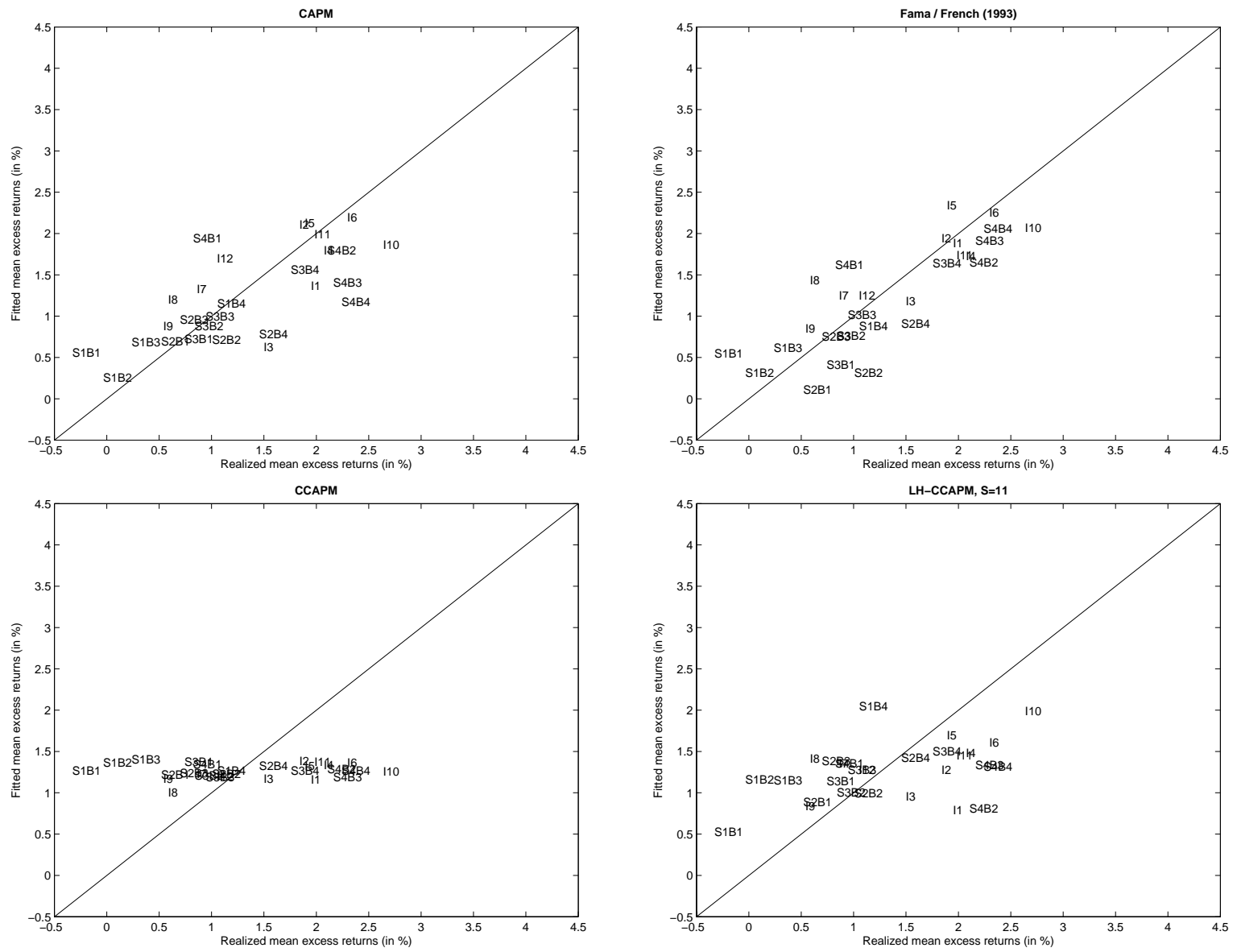

Note: The figure compares realized mean excess returns on 16 value and size as well as 12 industry portfolios to those predicted by the CAPM, the Fama and French (1993) model, and the linearized LH-CCAPM (with constant risk-free rate) at different horizons. The portfolios are depicted in the following way: e.g., S1B1 refers to stocks in the smallest size and book-to-market Quartiles, while S4B4 refers to stocks in the largest size and book-to-market Quartiles; industry portfolios are depicted as I plus the corresponding industry number running from 1 to 12 . Fitted excess returns are based on first stage GMM estimation with identity weighting matrix. The sample period is 1974:Q2 - 2001:Q1. 